\title{
Bridging the Grammar Gap: teaching English grammar to the iPhone generation ${ }^{1}$
}

\author{
BAS AARTS, DAN CLAYTON AND SEAN WALLIS
}

\section{University College London}

For second language learners, the value of the explicit teaching of English grammar has never been questioned. However, in recent times there has been dissent about whether or not to teach English grammar to native speakers. From the late 1960s onwards English grammar teaching in the United Kingdom largely disappeared from the curriculum, and was replaced by teachers focusing on students learning to express themselves. This was in the main not a bad thing, because it made students active participants in their own learning, and they were expected to think critically and express themselves well. The teaching of grammar, with its emphasis on rules, drilling and learning by rote, was seen as conformist, dull and unnecessary, and this view seemed to be confirmed by research into the effectiveness of grammar teaching.

However, the result of this has been the Grammar Gap: very few UK school teachers teaching English today have explicitly been taught grammar, and even if they have been, more often than not it was part of learning a foreign language. The result of this is that grammatical knowledge among school leavers in the UK seems to be on the decline, as a survey of undergraduates' grammar skills cited in an article by Clayton and Hudson (2010) for the Times Educational Supplement reveals.

\footnotetext{
Our evidence for this claim is a very simple test of grammatical knowledge that was taken by incoming first-year undergraduates first in 1986, and then in 2009. The test is based on a 23-word sentence in which students are asked to identify one example of a noun, one of a verb, and so on through fifteen grammatical categories including 'finite verb' and 'definite article'. In 1986, the typical undergraduate
}

in a language-oriented degree (such as linguistics or French) could identify 12 categories correctly, compared with only 8 for the non-language undergraduates. But in 2009, language specialists in the same institutions (Aston University and UCL) could only manage 10 categories, and no institution (out of 13 that took part) matched the 1986 figures.

The UK National Curriculum is the UK Government's specification of the curriculum in state schools, up to age 18. English Grammar has been an explicit - if frequently reworded - component of English language education since 1990. However, school teachers readily admit that they are ill-equipped to teach it. Hudson and Walmsley (2005: 616) write:

Most younger teachers know very little grammar and are suspicious of explicit grammar teaching. Not surprisingly, therefore, new recruits entering teacher-training courses typically either know very little grammar or have no confidence in their knowledge, presumably because they have picked it up in an unsystematic way. This situation raises obvious problems for the implementation of the official programme.

In a current research project at UCL we invited a number of motivated English teachers to a series of 'grammar training days' where they would be given training in basic concepts of grammar. At the first such event, aimed at A-level ('Advanced level') English teachers (i.e. those teaching 16-18-year-olds), only two out of twenty teachers present could recall ever being explicitly taught English grammar. Other teachers were self-taught, and reported struggling with different frameworks and advice. Part of the problem is that there is 
much confusion about what is meant by 'grammar'. UCL's Survey of English Usage (SEU) founded by Professor (now Lord) Randolph Quirk produced one of the most widely used English grammar books of all time, namely the Comprehensive Grammar of the English

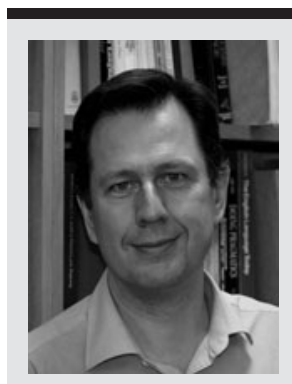

BAS AARTS is Professor of English Linguistics and Director of the Survey of English Usage at University College London. He is Vice-President for the Profession of the International Society for the Linguistics of English (ISLE), and with April McMahon and Wim van der Wurff he is editor of the journal English Language and Linguistics (CUP). His most recent publication is the Oxford Modern English Grammar (2011, Oxford University Press). Email:ucledba@ucl.ac.uk

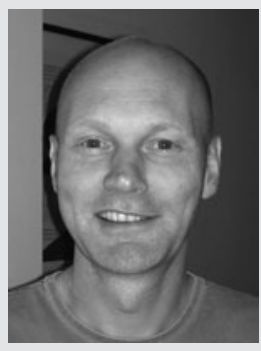

DAN CLAYTON is an A-level English Language teacher at the Sixth Form College in Colchester, a senior examiner for the $A Q A$ awarding body in the $U K$ and a Research Fellow at the Survey of English Usage on the Teaching English Grammar in Schools project. He also writes for the English and Media Centre's emagazine (aimed at A level English students) and for Nelson Thornes and Philip Allan Updates. Email:d.clayton@ucl.ac.uk

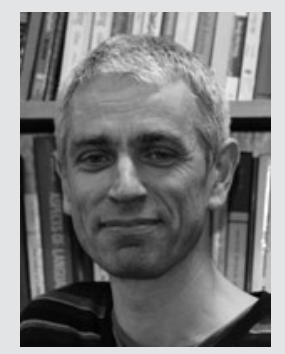
SEAN WALLIS is a Senior Research Fellow at the Survey of English Usage, and was responsible for the programming and design of the App. He supervised the completion of the ICE-GB and DCPSE parsed corpora and created the ICECUP software for exploring these corpora, a contribution which has opened new avenues of linguistic research. He is the author, with Bas Aarts and Gerald Nelson, of Exploring Natural Language (John Benjamins, 2002) and has written a range of articles on corpus linguistics methodology, from corpus design and annotation to experimental design and analysis.

Email: uclesew@ucl.ac.uk
Language, published in 1985 and co-authored by Sidney Greenbaum, Geoffrey Leech and Jan Svartvik. This was followed by A Student's Grammar of the English Language (Greenbaum and Quirk, 1990), an abridged version of the earlier book aimed at university undergraduates. We have kept up this tradition in recent decades with the publication of Greenbaum's Oxford English Grammar (1996) and Aarts's Oxford Modern English Grammar (2011), both based on the spoken and written material contained in the corpora that we have developed since 1959. However, these academic grammars vie for teachers' attention with style and usage guides such as The Elements of Style (Strunk and White, 1918) and their more recent descendants, which generally offer confusing and out-of-date advice (Pullum, 2009).

What was needed for teachers was an accessible and enjoyable way to learn about grammar themselves and to teach it to their students. In recent years information technology has offered opportunities to teach grammar in novel ways, and in 1996 the Survey of English Usage published the Internet Grammar of English, a complete grammar of English on the web, with a structured course and numerous exercises. This grammar has proved very popular, with well over three million hits over the years. The language used in explaining concepts is clear and engaging. The Internet Grammar contains static pedagogical content supplemented by animations and interactive exercises. In many respects it is a traditional course offered on a computer platform to provide a degree of excitement and self-evaluation. However, a problem with the Internet Grammar is implied by its name - the user has to sit in front of a computer connected to the internet at all times.

\section{Enter the App}

As computers become smaller and more portable, so-called 'smartphones' - essentially low-powered hand-held computers - have become popular. They offer a new way of studying grammar on the go because they can be used without the need for a continuous internet connection. Responding to these developments, the SEU published an 'App' in late August 2011, called the interactive Grammar of English (iGE), using the Internet Grammar as a basis. iGE is aimed at a broad audience, including:

- teachers and students of English as a native language; 
- teachers and students of English as a second language; particularly advanced learners;

- 'lay' people who are interested in English, and

- professional writers of English, such as journalists, editors and authors.

Creating the App was not simply a matter of converting the Internet Grammar website into a different form. Firstly, the size of the device and the fact that smartphones are directed by finger movements (tapping and swiping), rather than by mouse pointers, meant that the interface had to be re-thought.

Secondly, we rewrote the Internet Grammar by removing some sections and adding others to sharpen up the focus of the course. Longer paragraphs were split and the text was simplified to make explanations readable on a small screen. Example sentences were also shortened so that, as far as possible, a single example could fit across the screen in 'portrait' mode.

Thirdly, the set of exercises was extended and supplemented by many more authentic examples taken from the Survey's corpora. A certain amount of programming engineering went into the App to allow different types of exercises to be created with a broad range of actions required of the user (e.g. selecting words or a range of words in a text, as well as radio-button or check-button exercises). Exercises had to be dynamic, responsive and interesting, blending graphics with sound effects whenever a student tapped the screen.

Finally, the glossary, which was a minor element of the Internet Grammar, was extended and rewritten to reflect the course, becoming a combined search tool, reference and index in one. Whereas it is still possible to follow the course sequentially (and students are encouraged to do so), users can now search terms in the glossary, read a definition, and then either follow a cross-reference to another definition, or jump into the course to review teaching material relevant to the concept in question.

\section{A brief tour}

Probably the best way to describe this App is to take a tour. Figure 1 illustrates how the initial screen is presented to iPhone users (other smartphones with a comparable physical screen size are similar).

About half-way down the screen is a 'Quick Start' menu bar (Figure 1) which expands when tapped to offer a 'Start the course' option and other tools listed at the bottom of the screen ('Back', 'Contents', 'Exercises', 'Glossary' and

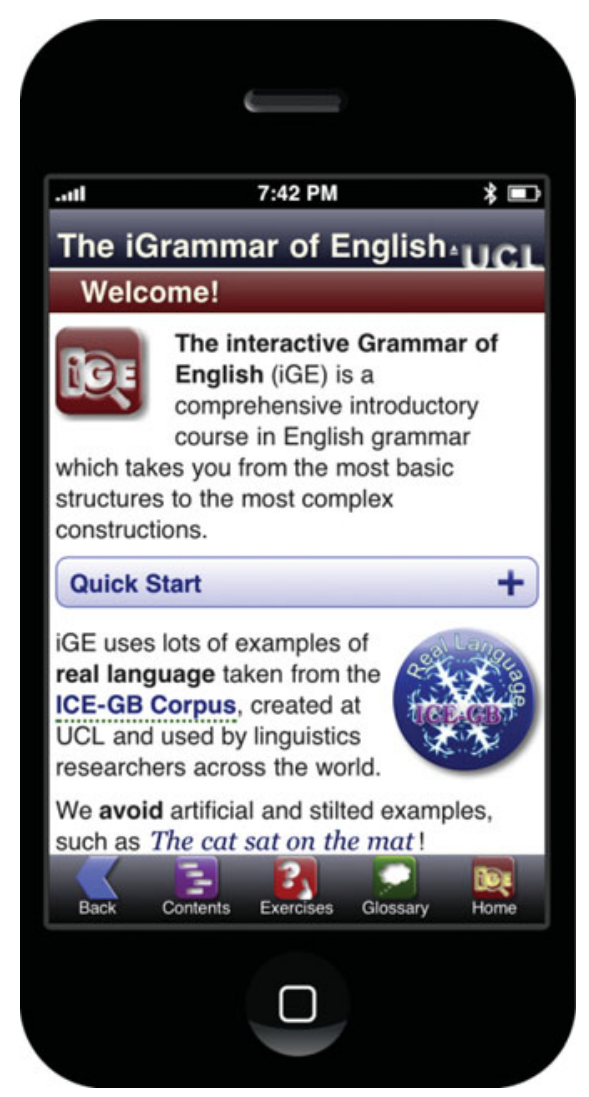

Figure 1. iGE Welcome screen (iPhone)

'Home'). The toolbar at the bottom of the display is optional: a quick double-tap of the display hides it, providing the user with more precious pixels of readable text. The screen scrolls gently in response to a swipe up or down.

Figure 2 displays a typical page of course material, with explanatory text presented in one font, and examples in a second. Coloured markers visually distinguish parts of speech: red=noun, blue $=$ verb, and so forth. Markers have different shapes (rounded or rectangular) to distinguish between word classes on the one hand, and phrases and clauses on the other. So, for example, a noun phrase is indicated by a red rectangle ('NP'), and the phrase will be marked out by red square brackets (shown here in bold):

\section{[NP the happy children]}

This coding is used systematically throughout the grammar.

Finally, as students progress to functions (such as Subject, Direct Object, etc.) we introduce a 


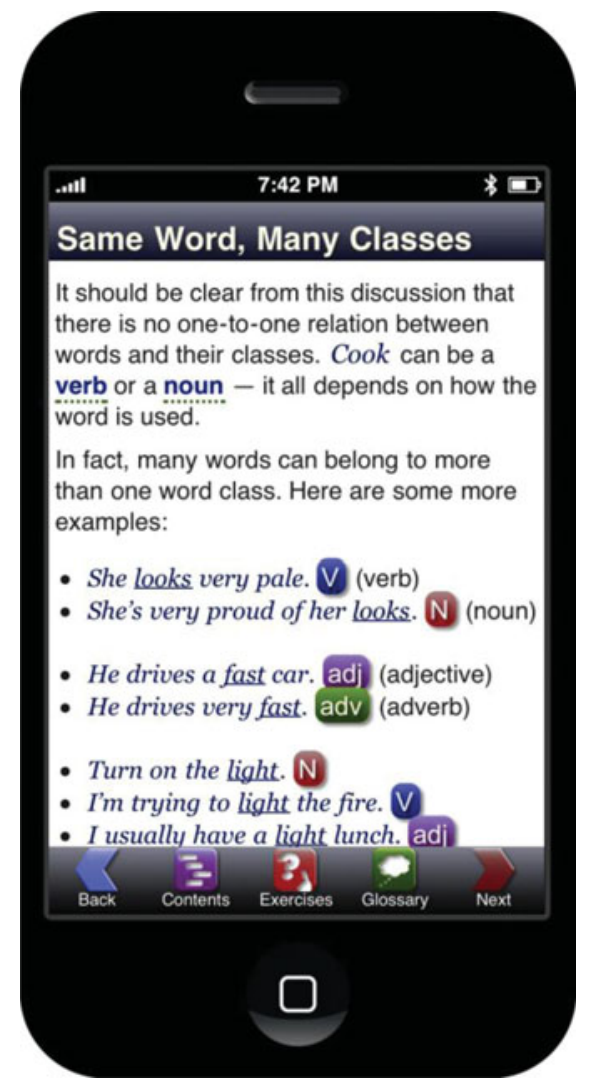

Figure 2. A page in the course

similar visual highlighting device: a rectangle with a white outline, visible here as a shading around the rectangles: Subject Predicate. Students are taught a series of novel concepts in rapid succession, and we have found that visual cues like this can be a useful aide-mémoire.

Figures 1 and 2 also display glossary links in the text. These words are in dark blue with a thick dotted green underline. Tapping the word will open the glossary with an explanation of the term in question. (To return, the user simply taps the 'Back' button.) Entries can be browsed with a touch, and expanded or contracted by tapping the title.

The glossary consists of an alphabetically ordered list of entries. Figure 3 displays the glossary entry for the particle $t o$. We can see that this entry includes an explanation of the concept and a couple of examples with the particles underlined and a marker attached. Below this are a series of cross-reference buttons that jump to other entries in the glossary and a link to relevant material in the course.

The glossary is split into 'pages' by initial letter, and the upper part of the display lets the user switch to another page with a simple tap.

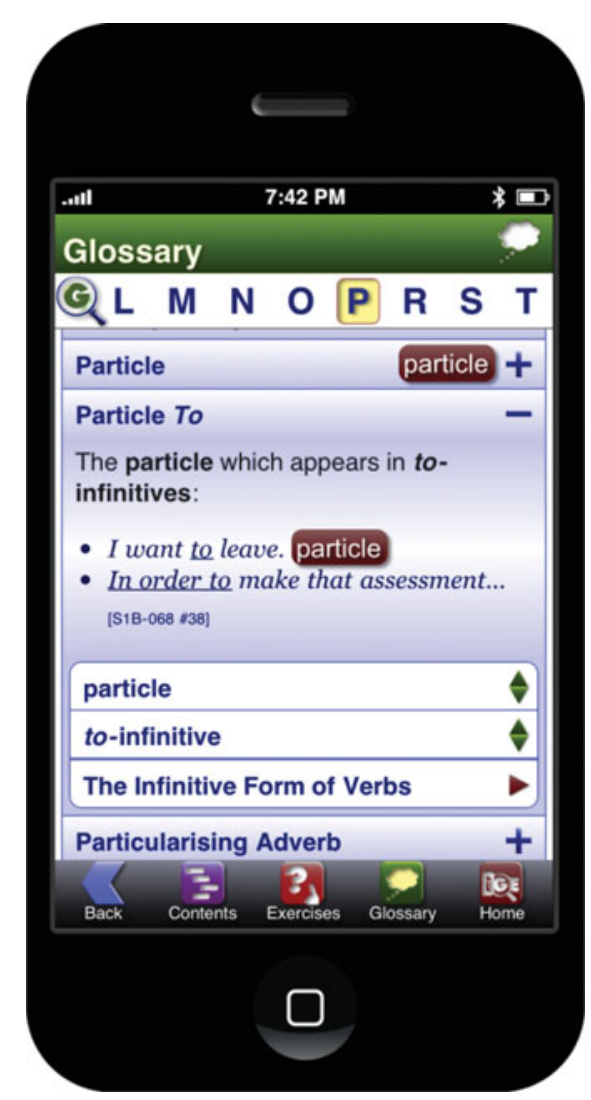

Figure 3. A glossary entry

Tapping the magnifying glass symbol (upper left, Figure 4) brings up the software keyboard, allowing the user to type a search term directly.

As noted above, scattered throughout the course are many exercises which ask users to perform a range of tasks, such as identifying nouns, adjectives and verbs, or heads of phrases etc., or classifying examples by some grammatical criterion. Figure 5 shows the very first exercise in the course, one that asks users to select all the nouns in the example sentence. The text in the example is large, to make the task of selecting words with a finger achievable. The ticking clock in the upper right hand corner is an optional feature, as is the automatic time-out after a set number of minutes or seconds. The use of a timer means that students who achieve a $100 \%$ score can still be motivated to improve by reducing their time. (Necessarily this also means that the interface must be very responsive, which was a challenge on some low-powered mobile phone devices.)

Users can tap a button to try particular exercises again. Uniquely, they will be presented with a different example sentence from the SEU's corpora. This prevents users being presented over 


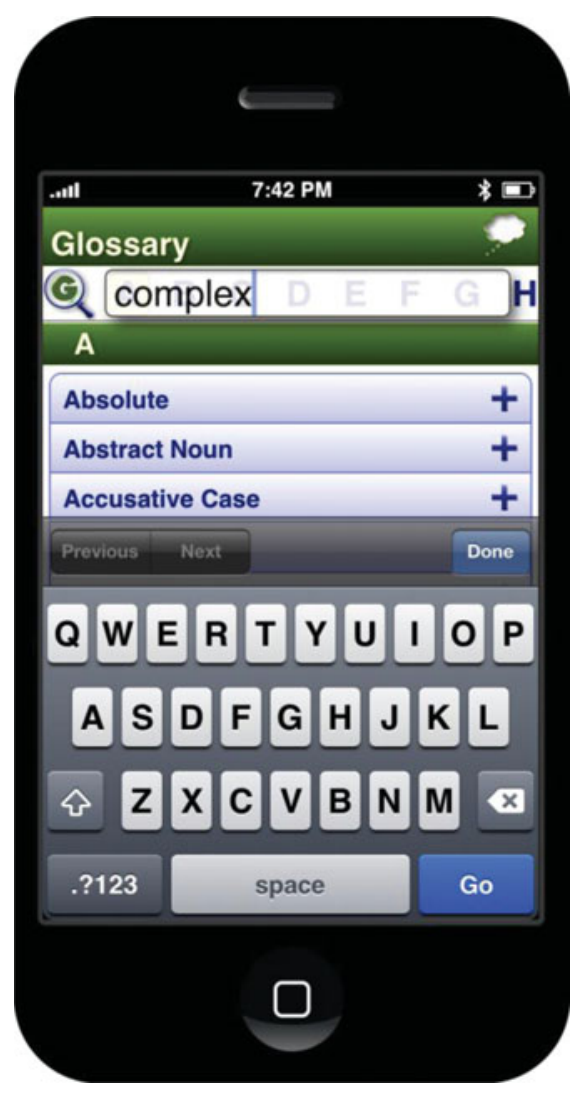

Figure 4. Searching the glossary

and over again with the same examples, as is the case with printed textbooks. The App allows users' highest scores and fastest times to be recorded for every exercise, and these scores can be reviewed in the 'Exercise overview' (available from the command bar). The feature encourages users to improve on their personal best scores.

Authentic examples can also help students see that the grammatical concepts they learn are relevant to their own language use, and that rules are not arbitrary, but informative. We strongly believe in learning through discovery, and that the App is an excellent way to get students to understand that grammar 'rules' are a shared framework which we use to communicate, rather than a set of restrictions that must be obeyed.

At the beginning of this article we noted how current UK secondary school teachers often find teaching grammar challenging (although this problem is not unique to the United Kingdom). iGE can help them in many ways. For example, the screen can be projected from an iPhone or iPad in a classroom, and exercises can be done collectively. We envisage the App as a resource for teachers to improve their own knowledge of grammar and gain ideas as to how they might teach grammar in the classroom, but also as a means of making grammatical analysis enjoyable for students of English. The numerous examples also allow iGE to be used for revision purposes.

iGE is published on Apple's App Store and Google's Android Market. Alongside the complete iGE is a free 'Lite' version containing the glossary and the first three sections of the course. We would very much encourage feedback from ET readers via the App's home page (see Websites below for details). We are continuing to improve iGE in the light of comments from users.

The publication of iGE is just one way in which the Survey of English Usage hopes to popularise English grammar to a new generation of teachers

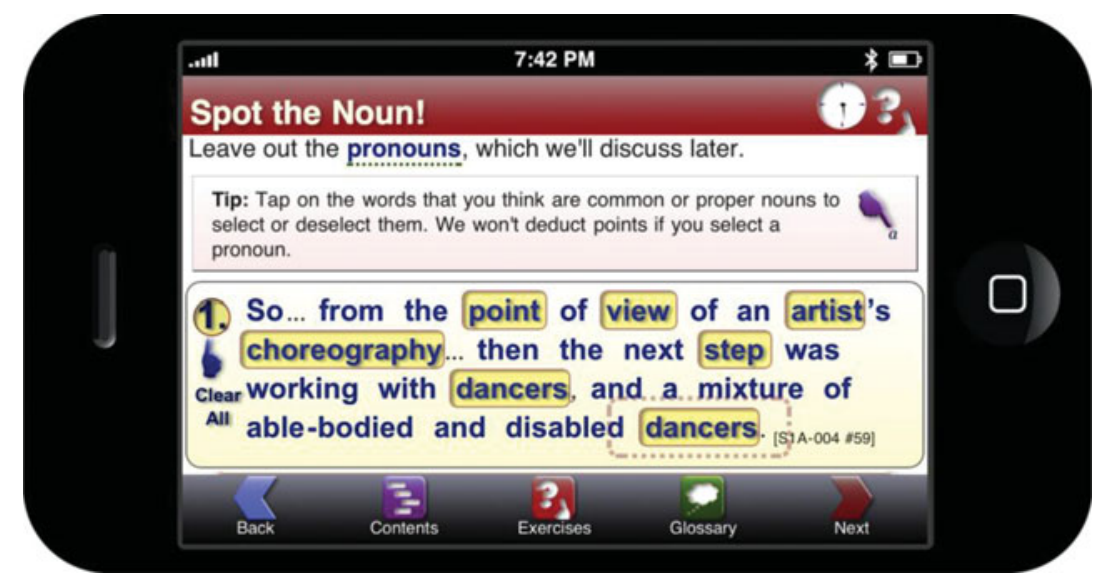

Figure 5. Testing your knowledge (in Landscape view) 
and students. Grammar is fun, and we hope our App will inspire them!

\section{Note}

1 The authors are based at the Survey of English Usage, UCL. The App is a spin-off of a project funded by the Arts and Humanities Research Council (AHRC) entitled Creating a Web-Based Platform for English Language Teaching and Learning, in which we are developing a website for classroom-based teaching as well as self-directed learning in secondary schools. For more information and relevant links, see Websites below.

\section{Websites}

The Internet Grammar of English, www.ucl.ac.uk/ internet-grammar.

The interactive Grammar of English (App home page), www.ucl.ac.uk/english-usage/apps/ige.

Creating a Web-Based Platform for English Language Teaching and Learning (research project), www.ucl.ac.uk/ english-usage/projects/grammar-teaching.

\section{References}

Aarts, B. 2011. Oxford Modern English Grammar. Oxford: Oxford University Press.

Clayton, D. \& Hudson, R. 2010. 'Give us a golden age of grammar.' Times Educational Supplement, 5, November 2010. Online at <www.tes.co.uk/article.aspx?storycode $=6062360>($ Accessed January 16, 2012).

Greenbaum, S. 1996. The Oxford English Grammar. Oxford: Oxford University Press.

Hudson, R. \& Walmsley, J. 2005. 'The English patient: English grammar and teaching in the twentieth century.' Journal of Linguistics 43(3), 593-622.

Pullum, G.K. 2009. '50 years of stupid grammar advice.' The Chronicle of Higher Education, April 2009. Online at $<$ http://chronicle.com/article/50-Years-of-StupidGrammar/25497 (Accessed January 16, 2012).

Quirk, R., Greenbaum, S., Leech, G. and Svartvik, J. 1985. A Comprehensive Grammar of the English Language. London: Longman.

—. \& —. 1990. A Student's Grammar of the English Language. London: Longman.

Strunk, W. \& White, E. B. 1918. The Elements of Style. London: Longman.

\section{CAMBRIDGE}

\section{Language Contact Yaron Matras}

Most societies in today's world are multilingual. 'Language contact' occurs when speakers of different languages interact and their languages influence each other. This book is an introduction to the subject, covering individual and societal multilingualism, the acquisition of two or more languages from birth, second language acquisition in adulthood, language change, linguistic typology, language

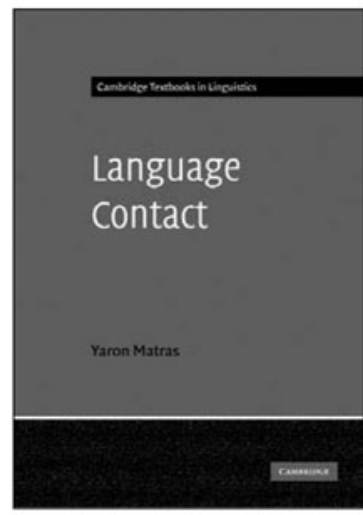
processing and the structure of the language faculty. It explains the effects of multilingualism on society and language policy, as well as the consequences that longterm bilingualism within communities can have for the structure of languages. Drawing on the author's own first-hand observations of child and adult bilingualism, the book provides a clear analysis of such phenomena as language convergence, grammatical borrowing, and mixed languages.

Lecturers can request inspection copies of this title.

Series: Cambridge Textbooks in Linguistics

$247 \times 174 \mathrm{~mm} / 384$ pages

Hardback | f60.00 | 9780521825351 Paperback | f23.99 | 9780521532211

Adobe eBook Reader | \$36.00 USD | 9780511629761

\section{www.cambridge.org}

